\title{
PHYSICAL FUNCTIONALITY AND SELF-RATED HEALTH STATUS OF ADULT PATIENTS WITH KNEE OSTEOARTHRITIS PRESENTING IN A PRIMARY CARE CLINIC
}

\author{
A.M. Ogunbode ${ }^{1}$, L.A. Adebusoye ${ }^{1}$, O.O. Olowookere ${ }^{1}$, T.O. Alonge ${ }^{1}$
}

\section{ABSTRACT}

BACKGROUND: Knee osteoarthritis is a chronic medical condition of public health importance in Nigeria which causes disability and impacts daily activities in the sufferers. This study aimed to describe the physical functionality and self-rated health status of adult patients with clinical knee osteoarthritis presenting at the Family Medicine Department, University College Hospital, Ibadan, Nigeria.

METHODS: This was a cross-sectional study of 400 respondents. Knee osteoarthritis was diagnosed clinically using the criteria of the American College of Rheumatology. Morbidities, self-rated health status and physical functionality of the respondents were also assessed.

RESULTS: Knee osteoarthritis was diagnosed in 46(11.5\%) respondents. Respondents with knee osteoarthritis significantly rated their health worse than those without knee osteoarthritis $(p<0.0001)$. Experience of pain, stiffness and performance of daily activities were significantly worse among respondents with knee osteoarthritis. Those who had knee osteoarthritis had significantly higher waist $(p<0.0001)$, hip $(p<0.0001)$ and knee circumferences $(p<0.0001)$ respectively. Logistic regression analysis showed increasing age $(O R=1.103 ; 95 \% C I=1.022-1.191)$, self-rated health worse than six months ago $(O R=12.562 ; 95 \% C I=1.178-125.243)$, experience of stiffness after waking up in the morning (OR=12.758; 95\% CI=3.572-45.569), stiffness after sitting/lying down/resting $(O R=21.517$; 95\% CI=2.213-209.220) and waist circumference $(O R=1.225 ; 95 \% C I=1.017-1.477)$ to be the most significantly associated with knee osteoarthritis.

CONCLUSION: Knee osteoarthritis significantly impairs the health and daily activities of adult patients in Ibadan, Nigeria. Healthcare workers need to screen adult patients routinely at first-contact to detect knee osteoarthritis clinically early and manage appropriately.

KEYWORDS: Family practice clinic, functionality, health status, knee osteoarthritis, Nigeria

DOI: http://dx.doi.org/10.4314/ejhs.v24i4.7

\section{INTRODUCTION}

Knee Osteoarthritis (OA) is a disease of global importance which leads to disability and affects the daily activities of individuals. Knee OA is very common and has an enormous impact not only on the health of the affected individual but that of the community (1). OA is a complex disease entity that is difficult to define and diagnose. The Subcommittee on Osteoarthritis of the American College of Rheumatology Diagnostic and Therapeutic Criteria Committee defined osteoarthritis (OA) as "A heterogeneous group of conditions that leads to joint symptoms and signs which are associated with defective integrity of articular cartilage, in addition to related changes in the underlying bone at the

${ }^{1}$ University College Hospital, Ibadan, Nigeria

Corresponding Author: L.A. Adebusoye, Email: larrymacsoye@yahoo.com 
joint margins". Clinically, the condition is characterized by joint pain, tenderness, limitation of movement, crepitus, occasional effusion, and variable degrees of local inflammation (2).

In knee OA evolution, even though the entire joint is implicated, the signature event appears to be loss of hyaline cartilage (3).Though clinical and radiological features may be used for diagnosis of knee OA (3).Assessment of knee OA using clinical features forms an important basis of diagnosis in resource-constrained countries because of the high cost of radiological investigation (3).

The commonest presenting complaints for knee OA are knee pain and stiffness. In 2000, Creamer found knee pain to be present in all the 69 respondents diagnosed with knee OA using the clinical diagnostic criteria of the American College of Rheumatology (ACR) (1). He also reported an increased prevalence of knee OA with advancing age (1). Most individuals with knee OA are usually over the age of 50 years presenting with pain and stiffness in the affected joint(s), which are worsened by activity and improved with rest (4).Early morning features lasting more than 30 minutes have also been reported in the literature as a common feature of knee OA (4).

Knee OA leads to physical disability through an interplay of several factors such as the severity of the disease condition, the presence and intensity of knee pain and other associated co-morbidities such as obesity which has been reported as the strongest modifiable risk factors of OA (5). Loss of physical capacity and derangement in the psychological, social and environmental factors has been implicated in the development of physical disability in knee OA (5).

Most cases of knee OA in Ibadan, Nigeria are attended to first by the primary care physician who often relies on radiologic evidence for diagnosis by which time severe and often irreversible destruction of the joint would have occurred. Similarly, the focus of management is often on salvaging the knee joint with less emphasis on the disability and health status of the sufferers. The aim of this study was to determine the physical functionality and health status of adult patients with clinical knee OA presenting at the University College Hospital, Ibadan, Nigeria.

\section{MATERIALS AND METHODS}

Study site: This study was carried out at the General Outpatient (G.O.P.) Clinic, Department of Family Medicine, University College Hospital (UCH), Ibadan, Nigeria. Ibadan is the largest city in Africa south of the Sahara with a population of 3.6 million people. $\mathrm{UCH}$ is the foremost teaching hospital in Nigeria and G.O.P. clinic functions as a primary care setting within the tertiary hospital. Most of the patients presenting in $\mathrm{UCH}$ for the first time are triaged and managed at the G.O.P. clinic while those requiring further specialist care are referred to other specialty clinics within the health facility.

Study design: A cross-sectional design was used for this study.

Study population: All consenting adult patients (18 years and above) who presented during the period of the study (January $15^{\text {th }}$ to March $30^{\text {th }}$ 2012) were recruited. Leslie and Kish formula for single proportion was used to calculate the sample size using the best estimate of knee OA in Nigeria (6). Thus, 400 patients were recruited. Those who were too ill to participate in the study and those who did not consent were excluded.

Sampling technique: Respondents who met the inclusion criteria were selected one after the other as they arrived at the clinic (consecutively).

Procedure: The respondents were interviewed with a semi-structured questionnaire which was pre-tested before its use. The American College of Rheumatology (ACR) criteria was used to diagnose knee OA clinically $(7,8)$. Detailed history and comprehensive physical examination of the respondents were carried out by the researchers, and focused laboratory investigations were added to arrive at the diagnoses. Their selfrated health status was assessed with the 'threeitem perception of illness scale' (9). Each item is graded from 1 to 5 (poor to excellent), which are aggregated into a composite score of perception of health (score $=3$ to 15$)(9,10)$. The perception of illness scale has a Cronbach's alpha coefficient of 0.65 (10). The Western Ontario and McMaster Universities Osteoarthritis (WOMAC) Index which is a disease-specific, tri-dimensional selfadministered questionnaire was used to assess their functionality (health status and health outcomes) (11).The WOMAC Index contains 24 questions, targeting areas of pain, stiffness and 
physical function and it is available in over 60 languages (11).

Anthropometric measurement: Height was recorded to the nearest centimetre with a measurement stand (stadiometer) which was positioned on a flat surface. Respondents were asked to remove their shoes, and their heels were positioned against the stand with their scapula, buttocks and heels resting against the wall and female respondents were asked to remove their headwears. Weight was measured with a weighing scale manufactured by Hana, China, and was recorded to the nearest $0.1 \mathrm{~kg}$. After the removal of their personal effects, respondents stood on the weighing scale which was placed on a flat horizontal surface. Readings were made by the researcher standing in front of the respondents and the zero mark was checked after every reading for accuracy. Intermalleolar and intercondylar distances were measured to the nearest centimetre. Body circumferences (waist, hip, knee and calf) were measured using a flexible non-elastic measuring tape and these were measured to the nearest 0.1 meters.

Ethical considerations: Informed consent of all the respondents was obtained before the examination and administration of questionnaires. Approval was sought and obtained from the head of Family Medicine Department, UCH, Ibadan.

Follow-up: All the respondents had their primary health complaints (reasons for encounter) addressed before the interview. Respondents needing additional treatment were referred to other specialty units within UCH, Ibadan.

Data analysis: SPSS (version 16) was used for data handling (entering, cleaning and analysis) after the questionnaires had been checked, sorted and coded serially at the end of each study day. Tables were generated to describe the categorical variables. Chi-square statistics was used to assess the association between categorical variables. Student's t-test was used to assess the association between continuous variables. The $\mathrm{p}-$ value of significance was set at $\leq 0.05$. Logistic regression analysis was used to explore the relationship between significant variables and knee OA.

\section{RESULTS}

Two hundred and thirty-eight (59.5\%) female and $162(40.5 \%)$ male respondents were interviewed giving a female to male ratio of $1.5: 1$. The mean $\pm \mathrm{SD}$ age was $47.3 \pm 16.4$ years (range was 18 to 90 years). The highest proportion of the 400 respondents interviewed, $93(23.2 \%)$ were aged 60 years and above. The majority of the respondents (64.2\%) were married and $35.0 \%$ had tertiary education. Elementary occupation such as cleaners and helpers; agricultural, forestry and fishery labourers; labourers in construction, manufacturing and transport; food preparation assistants; street and related sales and service workers and cleaners were the occupation of $48.8 \%$ of the respondents. The majority $(51.2 \%)$ lived above the Nigerian minimum wage of 18,000 Naira (\$120) per month.

Forty-six (11.5\%) respondents were diagnosed clinically with knee osteoarthritis using the American College of Rheumatology (ACR) diagnostic criteria. These constituted 10 (21.7\%) males and $36(78.3 \%)$ females. The mean \pm SD age of the respondents with knee OA $60.9 \pm 12.8$ years was significantly higher than those without knee OA $(45.5 \pm 16.1$ years $)(\mathrm{t}=$ $39.027, \mathrm{p}<0.0001)$. Respondents without knee OA on average walked more distances daily compared with those with knee OA (385metres vs 325metres, $\mathrm{t}=2.890, \mathrm{p}=0.090)$. Only 13 $(28.3 \%)$ of the respondents with knee OA engaged in physical activities such as walking $(17.4 \%)$, jogging $(4.3 \%)$, aerobics $(4.3 \%)$ and basketball $(2.3 \%)$. The average duration of their present episode of knee pain was 3 days $(2-50$ days). Various analgesics such as NSAIDS (91.3\%), Paracetamol (73.4\%), Opiods (34.8\%), topical $(47.8 \%)$ and injectable analgesics $(2.2 \%)$ were used by respondents in the previous one month. 
Table 1: Socio-demographic characteristics of respondents

\begin{tabular}{|c|c|c|}
\hline & $\mathrm{n}$ & $(\%)$ \\
\hline \multicolumn{3}{|l|}{ Age (years) } \\
\hline$<30$ & 79 & 19.8 \\
\hline $31-40$ & 79 & 19.8 \\
\hline $41-50$ & 76 & 19.0 \\
\hline $51-60$ & 73 & 18.2 \\
\hline$>60$ & 93 & 23.2 \\
\hline \multicolumn{3}{|l|}{ Marital status } \\
\hline Single & 79 & 19.8 \\
\hline Married & 257 & 64.2 \\
\hline Separated/divorced & 11 & 2.8 \\
\hline Widowed & 53 & 13.2 \\
\hline \multicolumn{3}{|l|}{ Educational status } \\
\hline None & 71 & 17.8 \\
\hline Primary school & 94 & 23.4 \\
\hline Junior secondary school & 3 & 0.8 \\
\hline Senior secondary school & 92 & 23.0 \\
\hline Tertiary & 140 & 35.0 \\
\hline \multicolumn{3}{|l|}{ Occupational classification (ILO-ISCO) } \\
\hline Managers & 2 & 0.5 \\
\hline Professionals & 18 & 4.5 \\
\hline Technicians and associate professionals & 10 & 2.5 \\
\hline Clerical support workers & 61 & 15.2 \\
\hline Service and sales workers & 38 & 9.5 \\
\hline Skilled agricultural, forestry and fishery workers & 8 & 2.0 \\
\hline Craft and related trades workers & 16 & 4.0 \\
\hline Plant and machine operators, and assemblers & 0 & 0.0 \\
\hline Elementary occupations & 195 & 48.8 \\
\hline Armed forces occupations & 8 & 2.0 \\
\hline *Unemployed & 44 & 11.0 \\
\hline \multicolumn{3}{|l|}{ Income } \\
\hline Below minimum wage ( $<18,000$ Naira per month) & 195 & 48.8 \\
\hline Above minimum wage ( $\geq 18,000$ Naira per month) & 205 & 51.2 \\
\hline \multicolumn{3}{|l|}{ Living arrangement } \\
\hline Alone & 34 & 8.5 \\
\hline With spouse & 240 & 60.0 \\
\hline With children/Grandchildren & 64 & 16.0 \\
\hline With relations/friends & 62 & 15.5 \\
\hline \multicolumn{3}{|l|}{ Financial support } \\
\hline Self & 140 & 35.0 \\
\hline Spouse & 82 & 20.5 \\
\hline Parents & 56 & 14.0 \\
\hline Children/Grandchildren & 107 & 26.8 \\
\hline Others & 15 & 3.8 \\
\hline
\end{tabular}

* Not categorized under International Labour Organization - International Standard Classification of Occupation (ILO-ISCO)

Table 2 describes the self-rated health of the respondents which was dichotomized into 'good' or 'poor'. When asked how they would rate their overall health, a higher proportion of respondents having knee OA $(76.1 \%)$ rated their health poorer than those without knee OA $(41.2 \%)\left(\chi^{2}=\right.$ 19.951, $\mathrm{p}<0.0001)$. Similarly, respondents with knee OA rated their health significantly poorer when compared with those without knee OA six months previously $(73.9 \%$ vs $36.4 \%) \quad\left(\chi^{2}=\right.$ $23.676, \mathrm{p}<0.0001)$. The physical health of those with knee OA was significantly poorer compared with those without knee OA $(60.9 \%$ vs $23.4 \%)$ $\left(\chi^{2}=28.437, \mathrm{p}<0.0001\right)$. 
Table 2: Self-rated health and knee OA

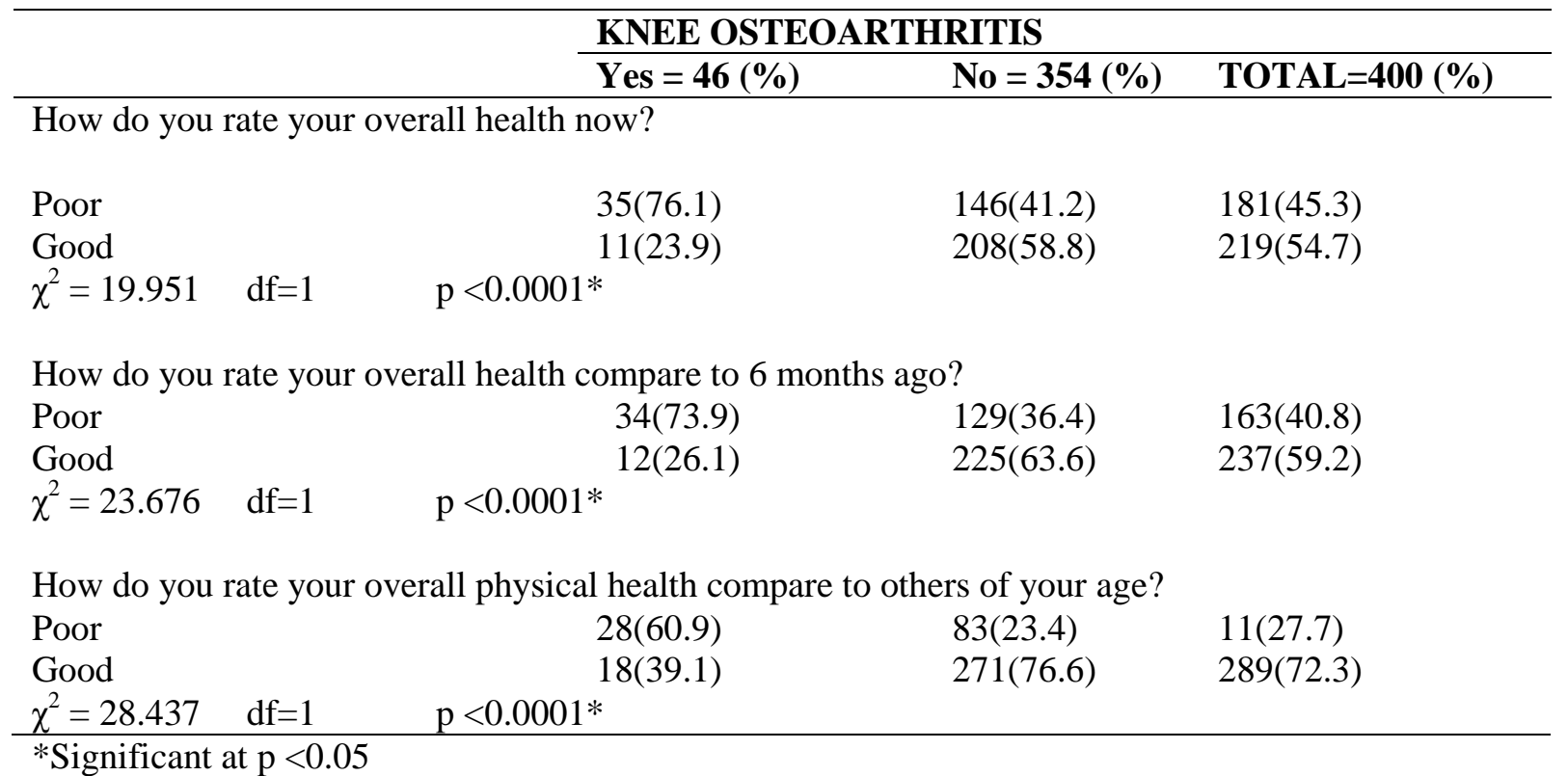

The physical functionality and health status of respondents is described in Table 3.This was assessed using the WOMAC $^{\mathrm{TM}}$ physical functionality questionnaire. In the pain subsection, respondents with knee OA significantly experienced more pain in their daily activities than those without knee OA did. Similarly, stiffness was experienced more among those with knee OA in the last 48 hours than in those without knee OA. Respondents with knee OA reported significant difficulty in performing their various daily physical activities and functions when compared with those without knee OA. 
Table 3: Physical functionality by clinical Knee Osteoarthritis

\begin{tabular}{|c|c|c|c|c|}
\hline & \multicolumn{2}{|c|}{ Knee Osteoarthritis } & \multirow[b]{2}{*}{ t- score } & \multirow[b]{2}{*}{ p-value } \\
\hline & $\begin{array}{l}\text { Yes }=46 \\
\text { Mean } \pm \text { SD }\end{array}$ & $\begin{array}{l}\text { No }=354 \\
\text { Mean } \pm \text { SD }\end{array}$ & & \\
\hline \multicolumn{5}{|l|}{ PAIN } \\
\hline When walking on a flat surface & $1.63(0.37)$ & $1.07(0.37)$ & 66.534 & $<0.0001^{*}$ \\
\hline When going up or down stairs & $3.15(1.09)$ & $1.51(0.85)$ & 140.549 & $<0.0001 *$ \\
\hline $\begin{array}{l}\text { At night while in bed (that is - pain that disturbs } \\
\text { your sleep) }\end{array}$ & $2.02(0.93)$ & $1.12(0.48)$ & 109.194 & $<0.0001^{*}$ \\
\hline While sitting or lying down & 2.43(1.07) & $1.29(0.62)$ & 112.951 & $<0.0001 *$ \\
\hline While standing & $2.37(1.20)$ & $1.30(0.81)$ & 62.487 & $<0.0001 *$ \\
\hline \multicolumn{5}{|l|}{ STIFFNESS } \\
\hline $\begin{array}{l}\text { How severe has your stiffness been after you first } \\
\text { woke up in the morning? }\end{array}$ & $2.28(0.86)$ & $1.07(0.35)$ & 314.114 & $<0.0001 *$ \\
\hline $\begin{array}{l}\text { How severe has your stiffness been after sitting } \\
\text { or lying down or while resting later in the day? }\end{array}$ & $1.83(0.93)$ & $1.02(0.17)$ & 218.043 & $<0.0001^{*}$ \\
\hline \multicolumn{5}{|l|}{ DIFFICULTY IN PERFORMING DAILY } \\
\hline When going down the stairs & $3.19(1.07)$ & $1.57(0.87)$ & 135.412 & $<0.0001 *$ \\
\hline When going up the stairs & $3.28(0.98)$ & $1.57(0.86)$ & 157.214 & $<0.0001^{*}$ \\
\hline When getting up from a sitting position & $2.69(0.89)$ & $1.36(0.67)$ & 149.764 & $<0.0001 *$ \\
\hline While standing & $2.39(1.06)$ & $1.36(0.82)$ & 59.104 & $<0.0001 *$ \\
\hline When bending to the floor & $1.76(0.95)$ & $1.30(0.63)$ & 18.825 & $<0.0001 *$ \\
\hline When walking on a flat surface & $1.59(0.78)$ & $1.06(0.34)$ & 65.462 & $<0.0001 *$ \\
\hline $\begin{array}{l}\text { Getting in or out of a car, or getting on or off a } \\
\text { bus }\end{array}$ & $2.57(1.03)$ & $1.33(0.79)$ & 94.085 & $<0.0001^{*}$ \\
\hline While going shopping/outing/market & $1.24(0.43)$ & $1.05(0.56)$ & 4.709 & $0.031 *$ \\
\hline When putting on your socks or stockings & $1.50(0.66)$ & $1.06(0.33)$ & 53.434 & $<0.0001^{*}$ \\
\hline When getting out of bed & $1.67(0.79)$ & $1.14(0.85)$ & 16.341 & $<0.0001 *$ \\
\hline When taking off your socks or stockings & $1.39(0.61)$ & $1.06(0.33)$ & 31.579 & $<0.0001 *$ \\
\hline While lying in bed & $1.52(0.66)$ & $1.12(0.81)$ & 10.250 & $0.001 *$ \\
\hline When getting in or out of the bathtub/room & $1.20(0.50)$ & $1.07(0.76)$ & 1.240 & 0.266 \\
\hline While sitting & $2.50(0.84)$ & $1.34(0.62)$ & 128.498 & $<0.0001^{*}$ \\
\hline When getting on or off the toilet & $2.19(0.91)$ & $1.21(0.57)$ & 104.300 & $<0.0001^{*}$ \\
\hline While doing heavy household chores & $2.35(1.10)$ & $1.33(0.66)$ & 80.902 & $<0.0001 *$ \\
\hline While doing light household chores & $1.19(0.45)$ & $1.01(0.12)$ & 37.683 & $<0.0001 *$ \\
\hline
\end{tabular}

*Significant at $\mathrm{p}<0.05$

Anthropometric measurements showed that the respondents having knee OA were significantly heavier $(74.4 \mathrm{~kg}$ vs $69.1 \mathrm{~kg} ; \mathrm{t}=8.035, \mathrm{p}=0.005)$ and had higher BMI $\left(29.4 \mathrm{~kg} / \mathrm{m}^{2}\right.$ vs $25.6 \mathrm{~kg} / \mathrm{m}^{2} ; \mathrm{t}=$ 23.411, p <0.0001) than those without knee OA. The knee circumferences of respondents with knee OA were significantly larger compared with those without knee OA; right knee circumference $(42.2 \mathrm{~cm}$ vs $39.8 \mathrm{~cm} ; \mathrm{t}=15.558, \mathrm{p}<0.0001)$ and left knee circumference $(41.9 \mathrm{~cm}$ vs $39.7 \mathrm{~cm}$; $\mathrm{t}=$
12.991, $\mathrm{p}<0.0001)$. The intercondylar $(4.1 \mathrm{~cm}$ vs $3.9 \mathrm{~cm} ; \mathrm{t}=0.108, \mathrm{p}=0.743)$ and intermalleolar $(4.6 \mathrm{~cm}$ vs $4.1 \mathrm{~cm} ; \mathrm{t}=0.250, \mathrm{p}=0.621)$ distances were greater in those with knee OA than in those without knee OA. Respondents with knee OA had higher Waist-Hip ratio $(0.91 \pm 0.06)$ compared with those without knee OA $(0.90 \pm$ $0.06)$, though this difference was not statistically significant $(\mathrm{t}=0.029, \mathrm{p}=0.865)$. 
Table 4: Anthropometric measurements of the respondents

\begin{tabular}{lllll}
\hline \multirow{2}{*}{ MEASUREMENTS } & \multicolumn{2}{l}{ KNEE OSTEOARTHRITIS } & & \\
\cline { 2 - 3 } & $\begin{array}{l}\text { YES } \\
\text { Mean } \pm \text { SD }\end{array}$ & $\begin{array}{l}\text { NO } \\
\text { Mean } \pm \text { SD }\end{array}$ & & \\
& $74.4 \pm 15.9$ & $69.1 \pm 12.2$ & 8.035 & $0.005^{*}$ \\
Weight $(\mathrm{Kg})$ & $159.5 \pm 6.8$ & $164 \pm 7.6$ & 18.084 & $<0.0001^{*}$ \\
Height $(\mathrm{cm})$ & $96.0 \pm 11.2$ & $88.7 \pm 10.3$ & 20.483 & $<0.0001^{*}$ \\
Waist circumference $(\mathrm{cm})$ & $106.2 \pm 12.4$ & $98.1 \pm 9.6$ & 27.063 & $<0.0001^{*}$ \\
Hip circumference $(\mathrm{cm})$ & $98.5 \pm 9.1$ & $101.3 \pm 5.3$ & 9.067 & $0.003^{*}$ \\
Right lower limb length $(\mathrm{cm})$ & $97.3 \pm 12.9$ & $100.5 \pm 9.1$ & 4.784 & $0.029^{*}$ \\
Left lower limb length $(\mathrm{cm})$ & $42.2 \pm 4.9$ & $39.8 \pm 3.8$ & 15.558 & $<0.0001^{*}$ \\
Right knee circumference $(\mathrm{cm})$ & $41.9 \pm 4.8$ & $39.7 \pm 3.9$ & 12.991 & $<0.0001^{*}$ \\
Left knee circumference $(\mathrm{cm})$ & $36.8 \pm 4.4$ & $36.3 \pm 4.0$ & 0.670 & 0.414 \\
Right calf circumference $(\mathrm{cm})$ & $37.6 \pm 5.1$ & $36.4 \pm 4.4$ & 2.551 & 0.111 \\
Left calf circumference $(\mathrm{cm})$ & $50.9 \pm 3.0$ & $52.4 \pm 3.7$ & 7.029 & $0.008^{*}$ \\
Right knee height $(\mathrm{cm})$ & $49.9 \pm 7.0$ & $52.0 \pm 5.7$ & 4.897 & $0.027^{*}$ \\
Left knee height $(\mathrm{cm})$ & $4.1 \pm 2.7$ & $3.9 \pm 2.5$ & 0.108 & 0.743 \\
Intercondylar distance $(\mathrm{cm})$ & $4.6 \pm 3.7$ & $4.1 \pm 2.5$ & 0.250 & 0.621 \\
Intermalleolar distance $(\mathrm{cm})$ & $0.91 \pm 0.06$ & $0.90 \pm 0.06$ & 0.029 & 0.865 \\
Waist Hip Ratio & $29.4 \pm 6.2$ & $25.6 \pm 4.8$ & 23.411 & $<0.0001^{*}$ \\
Body Mass Index & & & &
\end{tabular}

*Significant at $\mathrm{p}<0.05$

Logistic regression analysis showed increasing age $(\mathrm{OR}=1.103 ; \mathrm{CI}=1.022-1.191, \mathrm{p}=0.012)$, self-rated health worse than six months ago (OR $=12.562 ; \mathrm{CI}=1-125.243, \mathrm{p}=0.036$ ), experience of stiffness after waking up in the morning $(\mathrm{OR}=12.758 ; \mathrm{CI}=3.572-45.569, \mathrm{p}$ with knee OA.
$<0.0001)$, stiffness after sitting/lying down/resting $(\mathrm{OR}=21.517 ; \quad \mathrm{CI}=2.213-$ 209.220, $\mathrm{p}=0.008$ ) and waist circumference (OR $=1.225 ; \mathrm{CI}=1.017-1.477, \mathrm{p}=0.033)$ to be the most significantly associated. 
Table 5: Logistic regression analysis of significant variables associated with Knee Osteoarthritis

\begin{tabular}{|c|c|c|c|c|c|}
\hline & \multirow[b]{2}{*}{ B } & \multirow[b]{2}{*}{ p } & \multirow{2}{*}{$\begin{array}{l}\text { Odds } \\
\text { Ratio }\end{array}$} & \multicolumn{2}{|c|}{$95.0 \%$ C.I. } \\
\hline & & & & Lower & Upper \\
\hline Age & .0098 & $0.012 *$ & 1.103 & 1.022 & 1.191 \\
\hline Overall physical health right now & 1.415 & 0.282 & 4.118 & 0.312 & 54.272 \\
\hline Overall physical health compare to $6 \mathrm{mnths}$ ago & 2.524 & $0.036^{*}$ & 12.562 & 1.178 & 125.243 \\
\hline Overall physical health compare to others of your age & -0.751 & 0.520 & 0.472 & 0.048 & 4.658 \\
\hline Pain when walking on a flat surface & 0.389 & 0.746 & 1.475 & 0.140 & 15.540 \\
\hline Pain when going up or down stairs & -0.635 & 0.573 & 0.530 & 0.058 & 4.811 \\
\hline Pain at night while in bed & 0.310 & 0.694 & 1.364 & 0.291 & 6.389 \\
\hline Pain while sitting or lying down & -0.989 & 0.302 & 0.372 & 0.057 & 2.435 \\
\hline Pain while standing & -0.332 & 0.684 & 0.718 & 0.145 & 3.541 \\
\hline Stiffness after you woke up in the morning & 2.546 & $<0.001 *$ & 12.758 & 3.572 & 45.569 \\
\hline Stiffness after sitting/lying down/resting & 3.069 & $0.008 *$ & 21.517 & 2.213 & 209.220 \\
\hline Difficulty when going down the stairs & -1.468 & 0.365 & 0.230 & 0.010 & 5.524 \\
\hline Difficulty when going up the stairs & 3.421 & 0.057 & 30.586 & 0.901 & $1.039 \mathrm{E} 3$ \\
\hline Difficulty when getting up from a sitting position & 1.529 & 0.149 & 4.615 & 0.577 & 36.886 \\
\hline Difficulty in standing up & -0.229 & 0.797 & 0.795 & 0.139 & 4.553 \\
\hline Difficulty when bending to the floor & -0.342 & 0.591 & 0.710 & 0.204 & 2.476 \\
\hline Difficulty when walking on a flat surface & -0.742 & 0.629 & 0.476 & 0.023 & 9.688 \\
\hline $\begin{array}{l}\text { Difficulty getting in or out of a car or getting on or off } \\
\text { a bus }\end{array}$ & -0.303 & 0.708 & 0.739 & 0.152 & 3.597 \\
\hline Difficulty while going shopping/outing/market & -2.084 & 0.414 & 0.124 & 0.001 & 18.554 \\
\hline Difficulty when putting on your socks or stockings & -1.860 & 0.169 & 0.156 & 0.011 & 2.211 \\
\hline Difficulty when getting out of bed & -0.011 & 0.983 & 0.989 & 0.360 & 2.717 \\
\hline Difficulty when taking off your socks or stockings & 0.250 & 0.870 & 1.285 & 0.064 & 25.970 \\
\hline Difficulty in lying on bed & 0.633 & 0.125 & 1.883 & 0.838 & 4.232 \\
\hline Difficulty in sitting & 0.444 & 0.628 & 1.559 & 0.259 & 9.382 \\
\hline Difficulty when getting on or off the toilet & -1.042 & 0.296 & 0.353 & 0.050 & 2.491 \\
\hline Difficulty while doing heavy household chores & -0.066 & 0.914 & 0.936 & 0.281 & 3.122 \\
\hline Difficulty while doing light household chores & 0.607 & 0.795 & 1.835 & 0.019 & 178.863 \\
\hline Weight & 0.430 & 0.177 & 1.537 & 0.823 & 2.868 \\
\hline Height & -0.303 & 0.281 & 0.739 & 0.426 & 1.281 \\
\hline Waist circumference & 0.203 & $0.033^{*}$ & 1.225 & 1.017 & 1.477 \\
\hline Hip circumference & 0.036 & 0.617 & 1.036 & 0.901 & 1.192 \\
\hline Right lower limb length & -0.116 & 0.336 & 0.891 & 0.703 & 1.128 \\
\hline Left lower limb length & -0.003 & 0.945 & 0.997 & 0.903 & 1.100 \\
\hline Right knee circumference & 0.120 & 0.729 & 1.127 & 0.573 & 2.218 \\
\hline Left knee circumference & 0.225 & 0.518 & 1.253 & 0.633 & 2.481 \\
\hline Right knee height & -0.020 & 0.893 & 0.980 & 0.729 & 1.317 \\
\hline Left knee height & -0.002 & 0.977 & 0.998 & 0.883 & 1.128 \\
\hline BMI & -0.688 & 0.371 & 0.503 & 0.111 & 2.269 \\
\hline Constant & 41.261 & 0.334 & $8.306 \mathrm{E} 17$ & & \\
\hline
\end{tabular}

*Significant at $\mathrm{p}<0.05$

\section{DISCUSSION}

This hospital based study used the American College of Rheumatology (ACR) diagnostic criteria to diagnose Clinical knee Osteoarthritis (OA). The point prevalence of knee OA in this study was $11.5 \%$ with a female preponderance ratio of 3. This was less than that of a Nigerian community based cross sectional study (19.6\%) which also showed a female preponderance ratio of 1.2:1 (6). Knee OA has been shown to be commoner among the females due to several factors such as obesity and hormones like Insulin-like growth factor 1 (IGF-1) which declines significantly with age in women than men (12).

Self-rating of health is widely used to assess a person's health need $(13,14)$. Self rated health has also been shown to be a predictor of physical, social and mental health in patients with clinical Knee OA (15).Presence of knee OA was found to affect the self-rated health of the majority of respondents with knee OA adversely. This was shown by the report of 
worse rated health in respondents with knee OA at the time and six months prior to this study when compared with those without knee OA. Significantly, more than three-quarters of those with knee OA rated their health worse compared with less than a half of those without knee OA. Worsening of the overall health status among persons with knee OA has been reported in the literature and it varies with the type and number of joints affected $(16,17)$.

Western Ontario and McMaster Universities Osteoarthritis Index (WOMAC ${ }^{\mathrm{TM}}$ ) physical functionality questionnaire was used to assess the physical functionality of the respondents. Respondents with knee OA had poorer physical function when compared with those without knee OA, $p<0.0001$. This was in line with the study which reported that the majority of the respondents with moderate to severe knee OA had poor physical function with most of them stating that their knee OA interfered negatively with their role performance (6). Experience of pain in most aspect of daily activities such as walking, climbing up stairs, sitting and standing was significantly worse among participants with knee OA. Similarly, stiffness of the knee joint was experienced more frequently by respondents reporting clinical knee OA. The respondents with knee OA in this study also reported significant difficulty while doing daily physical activities. This was in agreement with the study by Creamer et al., 2000, using the same WOMAC disability score in which heavy domestic duties, descending stairs, rising from sitting and going shopping had the highest scores for self-reported difficulty; while the least were sitting and lying in bed (1).

Obesity was a major predictor of physical functional loss as there was significant direct correlation between disability and BMI and pain (1). Disability scores increased in persons having knee OA with increasing BMI compared with those having knee OA with normal BMI (1). Obesity was independently associated with disability and compounded disability from knee pain (18). Respondents in this study with knee OA were significantly heavier with higher waist, hip, and knee circumferences compared with those without knee OA. In addition, those with knee OA had significantly higher body mass index than those without knee OA. Association between obesity and knee OA had been shown in many studies $(19,20)$. Haq et al., in 2003 reported that during physical activity such as walking, three to six times the weight of the body is transferred across the knee joint and any increase in body weight can be multiplied by this factor (3).

In this study, multivariate analysis done using logistic regression analysis showed that the most significant variables associated with knee OA were increasing age $(\mathrm{OR}=1.103)$, higher waist circumference $(\mathrm{OR}=1.225)$ and self-rated health worse than six months ago (OR $=12.562$ ). The odds of experiencing stiffness after waking up in the morning with knee OA was almost 13 times $(\mathrm{OR}=12.758)$, while the odds of experiencing stiffness after sitting/lying down/resting was about 22 times $(\mathrm{OR}=21.517)$.

In conclusion, this study has shown that the presence of knee OA negatively impacts the daily activities, self-rated health status and functionality of the sufferers. Similarly, the significant association with increased adiposity (Waist-Hip ratio) and obesity identified in the study points to the need for routine health education to mitigate the public health impact of knee OA. Life-style modification should be part of the health information given to patients when presenting in the hospitals.

\section{REFERENCES}

1. Creamer P, Lethbridge-cejku M, Hochberg MC. Factor associated with functional impairment in symptomatic knee osteoarthritis. Rheumatology 2000; 39: 490496.

2. Altman R, Asch E, Bloch D, Bole G, Borenstein D, Brandt K et al. Development of criteria for the classification and reporting of osteoarthritis. Classification of osteoarthritis of the knee. Diagnostic and Therapeutic Criteria Committee of the American Rheumatism Association. Arthritis \& Rheumatism 1986; 29(8):10391049.

3. Bosomworth NJ. Exercise and knee osteoarthritis: benefit or hazard? Can Fam Physician. 2009 Sep;55(9):871-8.

4. Haq I, Murphy E, Dacre J. Osteoarthritis. Postgrad Med J. 2003;79:377-383 doi:10.1136/pmj.79.933.377.

5. Ettinger WH, Afable RF. Physical disability from knee osteoarthritis: the role of exercise as an intervention. Med Sci. Sport Exerc. 1994; 26 (12): 1435-1440.

6. Akinpelu AO, Alonge TO, Adekanla BA, Odole AC. Prevalence and pattern of symptomatic knee osteoarthritis in Nigeria: A Community-Based study. The Internet Journal of Allied Health Sciences and Practice. 2009; 7:3.

7. Heidari B. Knee osteoarthritis diagnosis, treatment and associated factors of progression: Part II. Caspian J. Intern Med 2011; 2 (3): 249-255.

8. Symmons D, Mathers C, Pfleger B. Global Burden of Osteoarthritis in the Year 2000. World Health Organization, Geneva 2003. Available from: URL: http://www.who.int/healthinfo/statistics/bod _osteoarthritis.pdf

9. Idler E: Self-assessed health and mortality: a review of studies. Int Rev Health Psychol 1992; 1:33-54.

10. Brody JA, Brock DB, Williams TF. Trends in the health of the elderly population. Annu Rev Public Health. 1987; 8: 211-34.

11. Bellamy N. WOMAC ${ }^{\mathrm{TM}}$ Questionnaire. 2004. Available at http://www.womac.org/

12. O'Connor MI, Hooten EG. Breakout Session: Gender Disparities in Knee Osteoarthritis and TKA. Clin Orthop Relat Res. 2011 July; 469(7): 1883-1885. doi: 
10.1007/s11999-010-1743-4. Available at http://www.ncbi.nlm.nih.gov/pmc/articles/P MC3111762/.)

13. DeSalvo KB, Bloser N, Reynolds K, He J, Muntner P. Mortality Prediction with a Single General Self-Rated Health Question. A Meta-Analysis J Gen Intern Med. 2006 March; 21(3):

267-275. doi: 10.1111/j.1525-1497.2005.00291.x

14. Arnadottir SA, Gunnarsdottir ED, Stenlund $\mathrm{H}$, Lundin-Olsson L. Determinants of selfrated health in old age: A population-based, cross-sectional study using the International Classification of Functioning. BMC Public Health 2011, 11:670 doi: $\quad 10.1186 / 1471-$ 2458-11-670. Available http://www.biomedcentral.com/14712458/11/670. Access date: 19-08-2013.

15. Riddle DL, Dumenci L. Self-rated health and symptomatic knee osteoarthritis over three years: data from a multicenter observational cohort study. Arthritis Care Res (Hoboken). 2013 Feb;65(2):169-76. doi: 10.1002/acr.21661.

16. Pretorious R, Rosenbaunm M. Clinical problem solving. In Rakel RE. Principles of
Family Practice, 6th ed. Philadelphia: WB Sanders, 2002: 275.

17. Dawson J, Linsell K, Zondervan P, Rose P, Randall T, Carr A et al. Epidemiology of hip and knee pain and its impact on overall health status in older adults. Rheumatology 2004; 43: $49-504$.

18. Jordan JM, Luta G, Renner JB, Linder GF, Dragomir A, Hochberg MC et al. Selfreported functional status in osteoarthritis of the knee in a rural southern community: The role of sociodemographic factors, obesity, and knee pain. Arthritis \& Rheumatism. 1996 August; 9 (4): 273-278. DOI: 10.1002/1529-0131(199608)9:4 <273::AID-ANR1790090412>3.0.CO;2-F

19. Felson DT, Anderson JJ, Naimark A, Walker AM, Meenan RF. Obesity and knee osteoarthritis. The Framingham Study. Ann Intern Med. 1988; 109: 18-24.

20. Sahyoun NR, Hochberg MC, Helmick CG, Harris T, Pamuk ER. Incidence of SelfReported Physician-Diagnosed Arthritis among women. American Journal of Public Health. 1999 March; 89:3. 